\title{
PERTANGGUNGJAWABAN SOSIAL PADA PERLAKUAN AKUNTANSI DI PERUSAHAAN UNTUK PENGEMBANGAN LINGKUNGAN MASYARAKAT
}

\author{
Roli Baranto \\ Stie Tribuana Bekasi
}

\begin{abstract}
ABSTRAK
Penelitian ini memiliki tujuan untuk menelaah bagaimana tanggung jawab sosial perusahaan (corporate social responsibility/CSR) untuk menerapan dan memperlakukaan akuntansi dalam upaya pengembangan masyarakat di lingkungan perusahaan PT Semen Tonasa. Sumber data didapatkan dari data primer dan data sekunder. Data primer berupa wawancara langsung dengan pihak perusahaan dan masyarakat. Sementara data sekunder berupa data yang diperoleh dari data internal perusahaan. Metode yang digunakan adalah metode kualitatif deskriptif. Hasil penelitian menunjukkan bahwa program CSR dalam bentuk comdev yang dilaksanakan oleh PT. Semen Tonasa sudah sangat membantu lingkungan masyarat dan telah dirasakan manfaatnya oleh masyarakat dan telah berjalan secara efektif, namun perlu ditindaklanjuti mengenai beberapa program yang pelaksanaannya masih berjalan tanpa adanya pengawasan ekstra dari pihak perusahaan. Laporan akuntansi CSR bersumber dari laba tahun berjalan sebesar 5\% sesuai dengan RUPS.
\end{abstract}

Kata Kunci: Tanggung Jawab Sosial Perusahaan; Pengembangan Masyarakat.

PENDAHULUAN

Tanggung jawab $\begin{array}{r}\text { sosial } \\ \text { perusahaan } \text { (Corporate }\end{array}$ Social
Responsibility/CSR)
merupakan
tindakan yang diberlakukan pada setiap
perusahaan sebagai rasa tanggung jawab
perusahaan terhadap sosial maupun
lingkungan yang mana perusahaan
tersebut berada, seperti melakukan
suatu kegiatan yang dapat
meningkatkan kesejahteraan lingkungan
masyarat dan menjaga lingkungan.

Seperti yang tercantum pada UU No. 40 Tahun 2007 tentang perseroan terbatas pasal 74 ayat (1) menyebutkan bahwa perseroan yang menjalankan kegiatan usahanya di bidang dan/atau berkaitan dengan sumber daya alam wajib melaksanakan tanggung jawab sosial dan lingkungan.

Perusahaan di Indonesia dalam menjalankan konsep CSR dipaksa oleh pemerintah, baik pemerintah daerah maupun pemerintah pusat serta regulasi 
yang mengaturnya. Paksaan yang dimaksud yaitu untuk transparan dalam menjalankan program tanggung jawab sosial perusahaan. Regulasi dan aturanaturan pemerintah dibuat dikarenakan masalah-masalah lingkungan yang sering terjadi di Indonesia yang diakibatkan oleh aktivitas perusahaan. Upaya yang dilakukuan perusahaan dalam mewujudkan tanggung jawab sosial pada lingkungan, antara lain berinvestasi pada sektor ramah lingkungan, pengolahan limbah maupun meningkatkan pengeluaran-pengeluaran sosial (social cost) yang memiliki tujuan untuk menjaga keseimbangan eksistensi antara perusahaan dengan lingkungan sosialnya.

Kesadaran tentang pentingnya penerapan CSR ini menjadi tren global seiring dengan semakin maraknya kepedulian yang mengutamakan stakeholders. Program CSR merupakan salah satu kewajiban yang harus dilaksanakan oleh perusahaan. Salah satu upaya perusahaan dalam menjalin hubungan yang baik dengan komunitas sekitarnya yaitu dengan melaksanakan kegiatan CSR yang berbasis pengembangan masyarakat atau community development.

Berbagai tekanan yang berasal dari masyarakat dan juga pemerintah untuk mendesak agar tercipta kesinambungan antara orientasi bisnis dengan kepedulian atas kondisi sosial dan lingkungan terus terjadi hingga saat ini. Tentu saja tekanan yang muncul berkaitan dengan keberagaman kepentingan yang melatarbelakanginya. Tetapi terdapat satu kesamaan mendasar dari kepentingan-kepentingan tersebut, yaitu adanya pertanggung jawaban perusahaan atas segala aktivitas bisnisnya terhadap masyarakat dan lingkungan. Secara umum, CSR merupakan kontribusi menyeluruh dari dunia usaha terhadap pembangunan berkelanjutan, dengan mempertimbangkan dampak ekonomi, social, dan lingkungan dari kegiatannya. Menurut Ghazali dan Chariri (2007) dalam stakeholders theory, perusahaan bukanlah entitas yang hanya beroperasi untuk kepentingannya sendiri namun dapat memberikan manfaat bagi para stakeholders-nya. Jadi, perusahaan tidak hanya meningkatkan labanya saja, tetapi juga harus memperhatikan masyarakat, 
lingkungan, pelanggan, sera pemasoknya. Sedangkan teori legitimasi lebih cenderung dalam perkembangan perusahaan kedepannya. Menurut Dowling dan Pletter, perusahaan perlu memperoleh legitimasi dari seluruh stakeholders dikarenakan adanya batasan-batasan yang dibuat dan ditekankan oleh norma-norma dan nilainilai sosial, dan reaksi terhadap batasan tersebut mendorong pentingnya analisis perilaku organisasi dengan memperlihatkan lingkung

(Adhiwardana dan Daljono, 2013)

Penelitian ini dilakukan di PT. Semen Tonasa yang bergerak dalam bidang industri manufaktur penghasil semen, dengan alasan bahwa perusahaan tersebut diketahui menghasilkan limbah industri dan berpotensi merusak lingkungan, sehingga perlu dikaji mengenai perlakuan akuntansi CSR dalam laporan tahunan perusahaan sebagai dasar perusahaan dalam melakukan pertanggungjawaban sosial dan lingkungan serta upaya yang dilakukan oleh PT.
Semen Tonasa dalam melakukan pengembangan masyarakat di lingkungan perusahaan.

Hasil penelitian ini diharapkan memberikan manfaat secara teoritis mengenai pengembangan akuntansi CSR dan memberikan manfaat praktis bagi perusahaan dalam penerapan akuntansi CSR terkhusus bagi PT. Semen Tonasa dalam menjalankan aktivitas CSR yang berkelanjutan.

\section{METODE PENELITIAN}

Dalam penelitian ini, pendekatan yang dilakukan adalah melalui pendekatan kualitatif. Penelitian kualitatif merupakan penelitian yang berusaha mengungkapkan gejala secara menyeluruh dan sesuai dengan konteks melalui pengumpulan data. Dalam penelitian kualitatif tidak ditemukan adanya angka- angka yang dianalisis menggunakan statistik, melainkan data diperoleh dari berbagai sarana yang dilakukan peneliti, seperti wawancara, dokumentasi, maupun pengamatan langsung. Metode penelitian yang digunakan dalam penelitian ini adalah studi deskriptif. 
Studi deskriptif dilakukan untuk mengetahui dan menjadi mampu untuk menjelaskan karakteristik variabel yang diteliti dalam suatu situasi. Tujuan dari penelitian deskriptif adalah membuat deskripsi atau menggambarkan faktafakta. Penelitian deskriptif ini akan memaparkan hal-hal yang berkaitan dengan penerapan CSR oleh PT. Semen Tonasa dalam upaya pengembangan lingkungan masyarat

Alat analisis menggunakan instrumen wawancara, dengan cara mengajukan beberapa pertanyaan kepada responden yang berkaitan dengan permasalahan penelitian. Teknik analisis yang akan dilakukan yaitu kualitatif deskriptif yang bersifat menggabungkan dari berbagai teknik pengumpulan data, seperti wawancara dan dokumen, serta sumber data yang telah ada untuk dapat disimpulkan.

Peneliti menggunakan metode deskriptif agar penelitian yang dilakukan mendapatkan hasil yang apa adanya dan objektif. Penelitian yang objektif dan hasil yang yang apa adanya di lapangan akan menunjukkan bahwa penelitian ini menjadi acuan bagi kelangsungan CSR ke depan.

\section{HASIL DAN PEMBAHASAN}

\section{Akuntansi Tanggung Jawab Sosial Perusahaan (Corporate Social Responsibility/CSR) \\ PT. Semen Tonasa telah} menetapkan blueprint CSR sebagai manual book pelaksanaan programprogram tanggung jawab sosial dan lingkungan yang didalamnya terdapat Strategic Flagship CSR Semen Tonasa yang mengambil tema "konservasi Energi Untuk Negeri” Programprogram Tanggung Jawab Sosial Lingkungan yang dilaksanakan oleh perseroan mengacu pada UU No. 40/2007 tentang Perseroan Pasal 74 dan penerapan konsep triple bottom lines yang menyelaraskan ekonomi, sosial, dan lingkungan. Perseroan berkomitmen sebagaimana tecantum dalam kebijakan perusahaan untuk berperan serta dalam pembangunan ekonomi berkelanjutan guna meningkatkan kualitas kehidupan dan lingkungan yang bermanfaat, baik bagi perseroan sendiri, komunitas setempat, maupun masyarakat pada umummnya. Pembiayaan dana tangung jawab sosial dan lingkungan dianggarkan sesuai dengan Rencana 
Kerja dan Anggaran Perusahaan (RKAP) tahunan.

\section{Program CSR untuk BUMN} adalah PKBL. Penyaluran Program Kemitraan dan Program Bina Lingkungan (PKBL) dananya disisihkan sebesar 4\% dari laba setelah pajak. Sumber dan penggunaan dana PKBL diatur dalam Peraturan Menteri No.02/MBU/7/2017. Dalam pelaksanaan Tanggung Jawab Sosial Lingkungan sesuai blueprint yang ditetapkan, perseroan telah menetapkan lima pilar utama yang didalamnya terdapat berbagai program dan kegiatan Tanggung Jawab Sosial Lingkungan. Pilar Tanggung Jawab Sosial Lingkungan tersebut adalah program Tonasa Mandiri, Tonasa Sehat, Tonasa Hijau, Tonasa Cerdas, Tonasa Bersahaja yang memiliki sasaran strategis.

Tabel 1

Penyaluran dana Bina Lingkungan PT. Semen Tonasa

\begin{tabular}{|l|l|l|l|}
\hline Tahun & $\begin{array}{l}\text { Laba Setelah } \\
\text { Pajak }\end{array}$ & Persentase & $\begin{array}{l}\text { Dana Program } \\
\text { PKBL }\end{array}$ \\
\hline 2016 & 603.207 .000 .000 & $2,12 \%$ & 12.709 .000 .000 \\
\hline 2017 & 274.758 .000 .000 & $4,62 \%$ & 12.844 .000 .000 \\
\hline Kegiatan & $\mathbf{2 0 1 6}$ & $\mathbf{2 0 1 7}$ \\
\hline Bantuan & 1.908 .120 .000 & 1.047 .420 .000 \\
\hline
\end{tabular}

\begin{tabular}{|l|l|l|}
\hline pendidikan/pelatihan & & \\
\hline $\begin{array}{l}\text { Bantuan Sosial } \\
\text { kemasyarakatan }\end{array}$ & 1.490 .942 .000 & 1.153 .928 .000 \\
\hline $\begin{array}{l}\text { Bantuan peningkatan } \\
\text { kesehatan }\end{array}$ & 584.142 .000 & 1.622 .117 .000 \\
\hline $\begin{array}{l}\text { Bantuan pelestarian } \\
\text { alam }\end{array}$ & 416.130 .000 & 839.997 .000 \\
\hline Bantuan sarana ibadah & 307.825 .000 & 175.000 .000 \\
\hline $\begin{array}{l}\text { Bantuan dana } \\
\text { bancana alam bantuan }\end{array}$ & 4.796 .659 .000 & 4.969 .030 .000 \\
\hline $\begin{array}{l}\text { Bantuan } \\
\text { pembinaan kemitraan }\end{array}$ & 42.000 .000 & 52.630 .000 \\
\hline $\begin{array}{l}\text { Jumlah } \\
\text { program BL }\end{array}$ & 812.000 & 1.106 .000 \\
\hline Beban administrasi & 4.797 .471 .000 & 4.970 .136 .000 \\
\hline Jumlah & & \\
\hline
\end{tabular}

Sumber Data: Diolah tahun 2018

Dari tabel di atas menunjukkan penyaluran dana yang dikeluarkan PT Semen Tonasa untuk kegiatan Bina Lingkungannya di mana tahun 2016 sebesar Rp. 4.797.471.000 dan tahun 2017 sebesar Rp. 4.970.136.000. sedangkan untuk program kemitraan sendiri yaitu pemberian pinjaman usaha untuk semua daerah yang masih dalam lingkup Sulawesi Selatan.

Tabel 2 Realisasi Kegiatan CSR di Ring 1 PT. Semen Tonasa

\begin{tabular}{|l|l|l|l|l|l|}
\hline $\begin{array}{l}\text { Desa/ } \\
\text { Kel }\end{array}$ & $\begin{array}{l}\text { Bidang } \\
\text { Kesehata } \\
\mathrm{n}\end{array}$ & $\begin{array}{l}\text { Bidang } \\
\text { Pendidik } \\
\text { an }\end{array}$ & $\begin{array}{l}\text { Bidang } \\
\text { Ekonomi }\end{array}$ & $\begin{array}{l}\text { Bidang } \\
\text { Lingkung } \\
\text { an } \\
\text { Infrastruk } \\
\text { tur }\end{array}$ & Ket \\
\hline $\begin{array}{l}\text { Biring } \\
\text { ere }\end{array}$ & $\begin{array}{l}\text { Pengoba } \\
\text { tan gratis }\end{array}$ & $\begin{array}{l}\text { Beasisw } \\
\text { a }\end{array}$ & $\begin{array}{l}\text { Bantuan } \\
\text { pinjaman } \\
\text { modal usaha }\end{array}$ & $\begin{array}{l}\text { Pembagia } \\
n \text { bibit } \\
\text { pohon, } \\
\text { Bedah }\end{array}$ & $\begin{array}{l}\text { Terlaksa } \\
\text { na }\end{array}$ \\
\hline
\end{tabular}




\begin{tabular}{|c|c|c|c|c|c|}
\hline & & & & rumah & \\
\hline Bontoa & $\left|\begin{array}{l}\text { Pengoba } \\
\text { tan gratis }\end{array}\right|$ & $\begin{array}{l}\text { Beasisw } \\
\text { a }\end{array}$ & $\begin{array}{l}\text { Bantuan } \\
\text { pinjaman } \\
\text { modal } \\
\text { dengan } \\
\text { bunga } \\
\text { rendah }\end{array}$ & $\begin{array}{l}\text { Perbaikan } \\
\text { jalan } \\
\text { berlubang } \\
\text {, } \\
\text { pembagia } \\
\text { n bibit } \\
\text { tanaman }\end{array}$ & $\begin{array}{l}\text { Terlaksa } \\
\text { na }\end{array}$ \\
\hline $\begin{array}{l}\text { Kalabira } \\
\text { ng }\end{array}$ & & $\begin{array}{l}\text { Beasisw } \\
\text { a }\end{array}$ & \begin{tabular}{|l} 
Bantuan \\
pinjaman \\
modal usaha \\
\end{tabular} & $\begin{array}{l}\text { Pembagia } \\
\text { n } \\
\text { tanaman }\end{array}$ & $\begin{array}{l}\text { Terlaksa } \\
\text { na }\end{array}$ \\
\hline $\begin{array}{l}\text { Samale } \\
\text { wa }\end{array}$ & $\left|\begin{array}{l}\text { Pengoba } \\
\text { tan gratis }\end{array}\right|$ & $\begin{array}{l}\text { Beasisw } \\
\text { a }\end{array}$ & $\begin{array}{l}\text { Bantuan } \\
\text { modal } \\
\text { usaha, } \\
\text { mempekerja } \\
\text { kan } \\
\text { masyarakat }\end{array}$ & \begin{tabular}{|l} 
Bedah \\
rumah, \\
pembuata \\
n jalan \\
rabat \\
beton, \\
penanam \\
an pohon
\end{tabular} & $\begin{array}{l}\text { Terlaksa } \\
\text { na }\end{array}$ \\
\hline $\begin{array}{l}\text { Tarawea } \\
\text { ng }\end{array}$ & $\begin{array}{l}\text { Pengoba } \\
\text { tan gratis } \\
\text { dan } \\
\text { sunatan } \\
\text { massal }\end{array}$ & $\begin{array}{l}\text { Beasisw } \\
\text { a }\end{array}$ & $\begin{array}{l}\text { Bantuan } \\
\text { pinjaman } \\
\text { modal usaha }\end{array}$ & $\begin{array}{l}\text { Pembagia } \\
\text { n r bibit } \\
\text { tanaman }\end{array}$ & \\
\hline $\begin{array}{l}\text { Tabo- } \\
\text { tabo }\end{array}$ & $\begin{array}{l}\text { PMT } \\
\text { dan } \\
\text { pengobat } \\
\text { an gratis }\end{array}$ & $\begin{array}{l}\text { Beasisw } \\
\text { a }\end{array}$ & $\begin{array}{l}\text { Bantuan } \\
\text { pinjaman } \\
\text { modal usaha }\end{array}$ & $\mid \begin{array}{ll}\text { Pengadaa } \\
\text { n } & \text { air } \\
\text { bersih }\end{array}$ & $\begin{array}{l}\text { Terlaksa } \\
\text { na }\end{array}$ \\
\hline Sapanag & \begin{tabular}{|l} 
PMT \\
posyand \\
u
\end{tabular} & $\begin{array}{l}\text { Beasisw } \\
\text { a }\end{array}$ & $\begin{array}{l}\text { Bantuan } \\
\text { modal usaha } \\
\text { dan } \\
\text { peralatan } \\
\text { usaha } \\
\\
\end{array}$ & $\begin{array}{l}\text { Jembatan } \\
/ \quad \text { Jalan } \\
\text { tani, } \\
\text { pembagia } \\
\text { n bibit } \\
\text { pohon, } \\
\text { dan } \\
\text { perbaikan } \\
\text { mesjid }\end{array}$ & Terlaksa \\
\hline $\begin{array}{l}\text { Bowong } \\
\text { cindea }\end{array}$ & $\begin{array}{l}\text { Sunatan } \\
\text { massal }\end{array}$ & $\begin{array}{l}\text { Beasisw } \\
\text { a }\end{array}$ & & \begin{tabular}{|l} 
Bantuan \\
dana \\
kemesjid, \\
bantuan \\
bencana \\
alam.
\end{tabular} & $\begin{array}{l}\text { Terlaksa } \\
\text { na }\end{array}$ \\
\hline
\end{tabular}

Sumber Data: Hasil Wawancara

Berdasarkan dari tabel realisasi kegiatan CSR di atas dapat kita lihat bahwa 5 pilar program perusahaan yaitu Tonasa Mandiri, Tonasa Sehat, Tonasa Hijau, Tonasa Cerdas, dan Tonasa Bersahaja sudah mereka terapkan di lingkungan masyarat meskipun masih ada beberapa program yang tidak terlaksana dibeberapa desa. Akan tetapi sebagian besarnya sudah berjalan dengan baik dan membantu masyarakat.

\section{D.2. Pengembangan Masyarakat dari}

\section{Program CSR PT. Semen Tonasa}

PT. Semen Tonasa melakukan pengembangan masyarakat dalam konteks pembangunan sumber daya manusia kearah kemandirian, karena tidak dapat dipungkiri bahwa kehadiran perusahaan di tengah kehidupan masyarakat dengan berbagai kegiatannya menimbulkan ketidaksetaraan sosial ekonomi anggota masyarakat lokal dengan perusahaan ataupun pendatang lainnya, sehingga diperlukan suatu kebijakan untuk meningkatkan daya saing dan kemandirian masyarakat lokal.

\section{Penerapan CSR PT Semen} Tonasa dalam upaya pengembangan masyarakat dapat dilihat dari kegiatankegiatan yang telah PT Semen Tonasa laksanakan dalam beberapa tahun ini. PT Semen Tonasa telah melaksanakan berbagai kegiatan diberbagai bidang yang telah mencakup dalam ruang lingkup program pengembangan masyarakat. Beberapa program yang dilakukan oleh PT. Semen Tonasa 
dalam pengembangan masyarakat adalah sebagai berikut.

Program community relation yang mengarah pada bentuk-bentuk kedermawanan perusahaan. Dari hubungan ini, dapat dirancang pengembangan hubungan yang lebih mendalam dan terkait dengan bagaimana mengetahui kebutuhan dan masalah yang ada di komunitas lokal sehingga perusahaan dapat menerapkan program selanjutnya. PT. Semen Tonasa turut berperan serta apabila terjadi bencana alam di desa-desa sekitar perusahaan, memberikan bantuan beras, dana tunai, membantu perbaikan rumah yang terkena bencana angin puting beliung dan memberikan bantuan pemadam kebakaran. PT. Semen Tonasa mempunyai forum-forum kegiatan CSR di setiap desa yang ada di daerah ring 1, di mana kegiatan CSR yang akan dilaksanakan, didiskusikan terlebih dahulu antara pihak manajemen perusahaan dan pihak perwakilan masyarakat, sesuai dengan pernyataan yang diberikan oleh pihak CSR PT Semen Tonasa. Wawancara yang dilakukan kepada Bapak H. Kadir sebagai manajer CSR menyatakan bahwa:

"Kami memiliki konsultan CSR, melalui konsultan ini dilakukan mediasi dua jalur, yaitu informasi dari konsultan dan forum-forum desa yang diwakili oleh tokoh pemda, wanita, tokoh masyarakat dan LSM. Sehingga keterwakilan elemen-elemen dari masyarakat inilah yang diadopsi masuk kesini"

Program community service, dalam kategori ini, program-program dilakukan dengan adanya pembangunan secara fisik, seperti sektor kesehatan, pendidikan, keagamaan, transportasi dan sebagainya yang berupa puskesmas, sekolah, rumah ibadah, jalan raya, dan sumber air. Inti dari kategori ini adalah kebutuhan yang ada di komunitas, dilakukan oleh komunitas sendiri dan perusahaan hanya sebagai fasilitator dari pemecahan masalah yang ada di komunitas. PT Semen Tonasa telah melaksanakan program pelayanan untuk memenuhi kepentingan masyarakat dalam bidang kesehatan dengan bantuan pengobatan gratis, sunatan massal,dan lain-lain, dalam bidang lingkungan mengadakan program air bersih dengan menyediakan sumur bor untuk masyarakat, mengupayakan penanaman 
bibit pohon dan penyiraman jalan guna menguangi debu yang mengusik masyarakat, dan mengadakan program bedah rumah bagi masyarakat yang rumahnya tak layak huni, di bidang pendidikan dengan program bantuan dana melalui beasiswa, bantuan perlengkapan sekolah dan lain-lain. Wawancara yang dilakukan kepada masyarakat atas nama Ibu Sabe' bahwa: "kami telah merasakan program pemeriksaan dan pengobatan gratis di rumah sakit PT. Semen Tonasa" Selain pengobatan gratis yang diberikan perusahaan kepada lingkungan masyarat, PT. Semen Tonasa memberikan bantuan pendidikan demi keberlanjutan masyarakat, alokasi bantuan pendidikan yang diberikan terdiri dari tingkat SD, SMP, SMA di Wilayah Ring 1 sebanyak Rp. 600.000 untuk SD, Rp. 800.000 untuk SMP, dan Rp.1.000.000 untuk SMA. Hal ini membuktikan bahwa program pengembangan masyarakat dalam bidang pendidikan menjadi perhatian khusus oleh PT. Semen Tonasa. Program community empowering, dalam kategori ini perusahaan memberikan program-program yang berkaitan dengan pemberian akses yang lebih luas kepada komunitas untuk menunjang kemandiriannya. PT Semen Tonasa memberikan bantuan kepada masyarakat dalam bidang ekonomi dengan memberikan bantuan kepada masyarakat dalam bidang ekonomi dengan memberikan bantuan modal kepada masyarakat, mengadakan pelatihan kerja dan mempekerjakan lingkungan masyarat. Ini didukung oleh pernyataan Bapak Hamzah selaku masyarakat yang mengatakan:

"Ada bantuan dana dengan tingkat bunga yang kecil dan ringan bagi masyarakat yang ingin membuka usaha dengan cara mengajukan proposal, saya sendiri pernah mendapatkan bantuannya dan membayar sampai lunas. Bantuan yang diberikan PT. Semen Tonasa lebih banyak dibandingkan bantuan yang dari pemerintah."

Dari kutipan wawancara tersebut, hal ini menunjukkan bahwa perusahaan PT Semen Tonasa sudah memperhatikan bentuk kepeduliannya melalui program CSR dengan cara memberikan bantuan langsung kepada masyarakat dengan bentuk modal usaha dengan bunga yang sangat rendah. Meskipun demikian masih ada yang harus ditindaklanjuti mengenai pendistribusian bantuan tersebut kepada 
masyarakat. Masyarakat mengklaim bahwa pendistribusian bantuan tersebut perlu pengawasan yang lebih, karena banyak masih ada yang menyalahgunakan dana bantuan tersebut.

Program CSR yang dilakukan oleh PT. Semen Tonasa telah sesuai dengan teori stakeholder bahwa, perusahaan bukanlah entitas yang hanya beroperasi untuk kepentingannya sendiri namun harus memberikan manfaat bagi stakeholder-nya. Dengan demikian, keberadaan suatu perusahaan sangat dipengaruhi oleh dukungan yang diberikan oleh stakeholder kepada perusahaan tersebut. Selain itu, teori legitimasi melengkapi program CSR yang lebih mengarah kepada program keberlanjutan ke depan. Menurut Dowling dan Pletter, perusahaan perlu memperoleh legitimasi dari seluruh stakeholders dikarenakan adanya batasan-batasan yang dibuat dan ditekankan oleh norma- norma dan nilai-nilai sosial, dan reaksi terhadap batasan tersebut mendorong pentingnya analisis perilaku organisasi dengan memperlihatkan lingkung

\section{PENUTUP}

Dalam penerapan program CSR dalam upaya pengembangan masyarakat PT Semen Tonasa telah memiliki Strategic Flagship yang berfokus pada 5 pilar yaitu Tonasa Mandiri, Tonasa Sehat, Tonasa Hijau, Tonasa Cerdas, dan Tonasa Bersahaja. Program CSR dalam bentuk Comdev yang dilaksanakan PT Semen Tonasa terdiri dari program bedah rumah, program pengobatan gratis, bantuan pinjaman modal usaha, program pemberian air bersih, pembangunan sanggar seni, program penghijauan. Dari program yang telah dilakukan di atas sudah membantu lingkungan masyarat dan telah dirasakan manfaatnya oleh masyarakat namun perlu ditindaklanjuti mengenai beberapa program yang pelaksanaannya masih berjalan tanpa adanya pengawasan ekstra dari pihak perusahaan dan beberapa program yang pelaksanaannya belum tepat sasaran. Untuk penyaluran dana CSR di PT Semen Tonasa sesuai dengan RUPS diambil 4\% dari laba setelah pajak untuk membiayai semua kegiatan(Adhiwardana dan Daljono, 2013) 
kegiatan yang masuk dalam program PKBL.

\section{DAFTAR PUSTAKA}

Andoyo, W.S. 2013. Pengaruh Corporate Social Responsibility terhadap Profitabilitas dengan Informasi Akuntansi sebagai variabel moderasi (Studi Empiris Perusahaan Go Publik di BEI). Vol. IV, No. 1.

Edoardus Satya Adhiwardana dan Daljono. 2013. Pengaruh Corporate Social Responsibility dan Kepimilikan Asing terhadap Kinerja Perusahaan. Diponegoro Journal of Accounting, Vol. II, No. II.

Responsibility (Tanggung jawab Sosial Korporasi). Cetakan Pertama. Anggota Ikatan Penerbit Indonesia (IKAPI)

Mursitama et al. 2011. Corporate Social Responsibility di Indonesia (Teoridan Implmentasi). Institute for Development of Economic and Finance (INDEF).

Rohmah, F. 2012. Analisis Penerapan Corporate Social Responsibility (CSR) Terhadap Profitabilitas Perusahaan (Studi Kasus PT Hanjaya Mandala Sampoerna Tbk). Univesitas Negeri Surabaya.

Samuel. 2011. Semen Tonasa Dinilai

Berat Sebelah salurkan dana CSR.http:www.kabartoraja.com/berita-luar/Sulawesiselatan/889- semen-tonasa-dinilaiberat-sebelah-salurkan-csr.

Yusuf, M. Y. 2017. Islamic Corporate

Social Responsibility (I-CSR) pada
Lembaga Keuangan Syariah (LKS).

Kencana: Indonesia 
Jurnal Parameter, Volume 3, No. 1 (2018)

ISSN : 1979-8865 